\title{
O CÓDIGO CIVIL PORTUGUÊS DE 1966 *
}

\author{
Prof. EUCLIDES DE MESQUITA \\ (Docente Livre e Professor Adjunto de Direito Civil. \\ Diretor do Instituto de Ciências Sociais e Direito \\ Comparado da Universidade.)
}

O Direito de Família, no nôvo Código Civil Português de 1966, modificou inteiramente a sistemática das matérias. Aderiu à classificação do Código Alemão de 1900, o qual se divide em 2 partes: uma parte geral e uma parte especial. Idênticamente, o Código Português compreende uma parte geral e uma especial, abrangendo esta última: Direito das Obrigações, Coisas, Família e Sucessões. Foi o nôvo Código mais fiel que o brasileiro àquela sistemática, pois no Código Brasileiro, embora adotando o sistema do B.G.B., a classificação obedeceu a outra ordem, começando a parte especial pelo Direito de Família, Coisas, Obrigações e Sucessões.

Esta sistemática, como se sabe, é completamente diversa daquela adotada pelos Códigos Francês e Italiano, e nunca é demais assinalar que o modêlo tudesco apresenta maior clareza e propriedade que os outros.

Basta ver, verbi gratia, que no modêlo francês o casamento é tratado no Livro III, Título III - dos Contratos e Obrigações Convencionais em Geral - técnica, aliás, também adotada pelo antigo Código Português de 1867, quando, no Livro II - Dos Direitos que se Adquirem por Facto Próprio e de Outrem Conjuntamente - que trata das diversas modalidades de contrato - no Título II, Capítulo I, inclui o casamento como uma das formas dos contratos em particular.

No Código Italiano de 42, mereceu a Família um tratamento mais nobre. Embora não se perfilhe ao sistema do B.G.B., abre o código seu livro I com - Delle Persone e della Famiglia - sem relegar a matéria a uma indevida colocação em departamentos inapropriados à sua natureza.

* Conferência proferida a 5 de fevereiro de 1969, no ciclo promovido pelo Instituto de Ciências Sociais e Direito Comparado. 
O nosso TEIXEIRA DE FREITAS já reconhecera a necessidade de um tratamento especial à Família, em sua Consolidação das Leis Civis, contratada com o Govêrno Imperial em 1855, e, em sua Parte especial, o Capítulo I regula - Os Direitos Pessoais nas Relações de Família - e também no "Esbôço" deu singular destaque à Família, quando, na parte especial, Livro II, Seção II, se ocupou - "Dos Direitos Pessoais nas Relações de Família".

Releva observar que o nôvo Código Português é simples e compreensivo, na sua conceituação jurídica e na redação.

Em alguns casos, melhorou muito o aspecto e a clareza de expressão, embora não contasse, como o Código de 1867, com a pena castiça de HERCULANO a the retocar a linguagem, como o fêz RUI com nosso Código de 1916.

Já não quero referir a contextura morfológica, a boa disposição das matérias, a clareza incisiva e, quase sempre, sóbria dos preceitos, a largueza das sínteses contidas em cada dispositivo. São ditames elementares da lógica e técnica jurídicas bastante comuns, que dispensam maior elogio; mas as condições de caráter mais geral, que saem da órbita da técnica e da forma externa que, dizendo respeito à porção mais íntima do tecido orgânico do Código, oferecem, por várias faces, o aspecto de condições sociológicas, porque apresentam o Direito em função como fôrça social; essas condições, é bom que se recordem, porque nem sempre têm em mente os confeccionadores de códigos.

E foi, já naquela época, que CIMBALI propunha a criação de um código de direito privado social, em substituição ao código de direito privado individual, atualmente existente.

E o nôvo Código Português, na reiterada manifestação de ANTUNES VARELLA, visa a "refletir a tendência social do direito moderno, procurando conciliar o respeito que a lei deve à liberdade individual com as supremas exigências de uma ordem fundada na Justiça e na reta convivência entre os homens e harmonizando os benefícios da iniciativa privada com os deveres de solidariedade impostos pelo bem comum, pela paz social e pela segurança do direito".

No que respeita ao Direito de Família, mereceu o mesmo aprofundado estudo dos juristas portuguêses que, já de há muito, tentavam modificar a estrutura do Código Civil de sua pátria, sendo de assinalar a primeira tentativa, nesse, sentido, em 1903, e a reforma levada a cabo pelo Decreto n. ${ }^{\circ} 19.126$ de 16 de dezembro de 1930 - que introduziu alterações em 175 artigos do antigo Código de 
1867, vários dêles referentes ao Direito de Família, na seqüência de um Projeto devido à autoria do Dr. ANTONIO PINTO DE MESQUITA, advogado no Pôrto.

Preparados para a reforma total, os juristas portuguêses dedicaram-se à difícil tarefa, através de diversos anteprojetos parcelares, sendo principal autor de vários dêsses anteprojetos parcelares o jurista GUILHERME BRAGA DA CRUZ, versando "Capacidade e Patrimônio dos Cônjuges", "Problemas Relativos ao Regime de Bens no Casamento", - "Doações Entre Casados", "Relações Pessoais Entre os Cônjuges e Sua Capacidade Patrimonial", seguindo-se o Dr. PIRES DE LIMA, que apresentou os seguintes anteprojetos parcelares: "Filiação, Poder Paternal, Tutela de Menores, Emancipação e Maioridade", e ainda ADRIANO VAZ SERRA, com "Obrigações de Alimentos".

Todos os anteprojetos foram modificados, em grande parte, ao se transformarem em Projeto, com 2.334 artigos e é compensador verificar que o estudo dos anteprojetos parcelares foi levado tão a sério que quase nenhuma alteração sofreu o Projeto em sua transformação no Código atual. Basta acentuar ser o número de artigos do Projeto e do Código o mesmo, havendo apenas pequenas modificações de redação ou acréscimo de alguns incisos, sem alterar a estrutura fundamental do Projeto. Assim, verbi gratia, no Direito de Família, que se estende do artigo 1.576 até o artigo 2.023, em um total de 447 artigos, apenas merecem alterações os artigos 1.576, $1.577,1.578,1.581,1.593,1.601,1.618$, n. $^{\circ} 20,1.624,1.627$, $1.633,1.638,1.640,1.666,1.672,1.678$, letra $9,1.688,1.701$, $1.778,1.783$ e poucos outros, num total de aproximadamente vinte e poucos, o que representa índice mínimo de modificações para um total de 447 artigos, como vimos acima.

É de notar que essas modificações versam sôbre redação e meIhor distribuição do texto, sem jamais alterar a essência do dispositivo jurídico. Assim é que, para exemplificar, o art. 1.576 do Projeto tinha a denominação de "Âmbito das Relações Familiares" e subtítulo "Fundamento da Família", passando o Código a acolher o mesmo artigo, com a seguinte redação: "Fontes das Relações Familiares", o que nos parece melhor redigido, em face do texto que diz: "São fontes das relações jurídicas familiares o casamento, ○ parentesco, a afinidade e a adoção".

Ainda outro exemplo: na definição de parentesco, o Projeto consigna: "Parentesco é o vínculo que une duas pessoas que descendem uma da outra ou procedem de um progenitor comum", e o Código diz: "Parentesco é o vínculo que une duas pessoas, em con- 
seqüência de uma delas descender da outra ou de ambas procederem de um progenitor comum", e que nos parece melhor redação. Outras modificações consistiram em supressão de alguns incisos, que afeiavam o Projeto ou contrariavam princípios jurídicos consagrados e constantes do Projeto. Assim é que, do art. 1.601, sôbre "impedimentos dirimentes absolutos", foi supressa a letra $\mathbf{d}$ final que afirmava: "As ordens maiores conferidas em harmonia com as leis canônicas, e os votos solenes ou equiparados, feitos nas mesmas condições, salva a dispensa concedida pela autoridade eclesiástica competente", o que nos parece acertado, em face da separação da Igreja do Estado, sem embargo da Concordata de 1940, que reconhece o chamado casamento católico ou concordatário.

Foram dos mais trabalhados e exaustivamente retocados $\in$ pulemizados os assuntos pertinentes ao Direito de Famíilia, em o nôvo Código, apresentados que foram cêrca de 22 trabalhos preparatórios pelos Membros da Comissão e da Comissão Revisora, destacando-se GUILHERME BRAGA DA CRUZ, JORGE FERNANDO PESSOA, PIRES DE LIMA, MANUEL GONÇALVES PEREIRA, ADRIANO VAZ SERRA e MANUEL DUARTE GOMES DA SILVA. Tão profundo foi o estudo, tão interessados os responsáveis pela gestação do Código, na parte relativa ao Direito de Família, que mereceu de ANTUNES VARELLA afirmar: "Interferindo na sociedade familiar para disciplinar as relações entre os rônjuges ou entre pais e filhos, fixando o destino dos bens de cada um de nós para além de sua morte, tutelando os direitos fundamentais da personalidade, o Direito Civil toca assìduamente nas camadas mais profundas da nossa existência terrena e constitui um dos mais fortes redutos da pessoa humana contra o colosso cada vez maior que é o. Estado moderno", sendo êste um dos mais atendidos departamentos do nôvo Código.

\section{CASAMENTO}

O Código Português, em seu artigo 1.577, define casamento, como "o contrato celebrado entre duas pessoas de sexo diferente que pretendem constituir legitimamente a família mediante comunhão plena de vida". No Projeto, a definição era um pouco diferente e êste é um dos poucos artigos que sofreram alteração.

O Projeto dizia: "Casamento é o contrato celebrado entre duas pessoas de sexo diferente que pretendem constituir legitimamente a família, mediante uma comunhão plena de vida e tem como fim precípuo a procriação e educação da prole". É curioso que o Código tenha definido o casamento, mantendo, aliás, neste ponto, a tradição do Código de 1867. De todos os códigos que perlustrei 
em nenhum encontrei a definição de casamento, o que faz parecer acertada a observação de ENRIQUE DIAS DE GUIJARRO, em seu "Trałado de Derecho de Família", quando afirma que: "A definição da família e do casamento fica reservada a obras de caráter doutrinário e não a figurar expressamente nas leis". Êste comportamento legislativo que é seguido por todos os códigos atuais, como $\circ$ alemão, o suíço, o francês, o italiano, o grego, o argentino, o espanhol, - uruguaio, e o próprio Código de Direito Canônico, canônes 1.012 e seguintes, e o brasileiro, inclusive o nosso Projeto, explica-se, não só porque é de boa técnica evitar as definições, senão porque responde à orientação do Código Civil Francês, que melhor considera as relações de pessoa que a família em conjunto, como o revela a distribuição das matérias do Livro Primeiro daquele Código, destinado a tratar das pessoas e cujas subdivisões carecem de uma epígrafe compreensiva dos vínculos familiares que são desenvolvidos independentemente, como situações jurídicas isoladas e com vitalidade própria. A legislação moderna supera êste conceito individualista. A evolução sociológica e filosófica, como também o estudo sistemático e orgânico das normas jurídicas que regem a Família, conduz a que se aprecie a unidade do núcleo e que se atribua uma entidade superior a de seus membros.

Assim, há surgido uma profunda renovação que se exterioriza nas leis e na metodologia das obras que versam o Direito de Família.

O Código Português não acompanhou essa evolução: ateve-se a princípios individualistas.

A Comissão Revisora ao Anteprojeto Brasileiro de ORLANDO GOMES, no Relatório apresentado ao sr. Ministro da Justiça, afirmava que: "a família moderna requer, positivamente, tratamento legal mais afeiçoado à sua composição e tessitura".

"Organizada em sentido mais social, voltada fundamentalmente para a prole, reclama estruturação jurídica que the acompanhe as transformações de harmonia com a evolução dos costumes".

Melhor seria que se conservasse a redação original do Projeto Português, cuja frase final foi supressa e que dizia: "que tem como fim primário a procriação e educação da prole". Melhor seria ainda que $\circ$ Código evitasse, no todo, a definição, deixando o encargo à doutrina. É ainda de convir que o Código se absteve intencionalmente, de qualquer referência aos direitos da "companheira", direito consagrado expressamente no Código Mexicano, art. 1.635, e no Projeto Brasileiro, art. 668. 
É preciso acentuar que profundas modificações aguardam o Direito de Família e o Código Português não fêz eco dessas imensas perspectivas. Duas manifestações originais apareceram durante o corrente século a respeito da regulamentação legal da Família: a inclusão de normas sôbre a Família nas constituições políticas dos Estados, como é o caso do Brasil, conforme o Título IV, art. 167 e segs. da Constituição de 67, e o cisma do Direito Civil, com a autonomia das regras sôbre a Família. Ambos os movimentos se vinculam com processos gerais e políticos, ainda que de alcance distinto: universal, o primeiro, que tende a apresentar uma estrutura integral do Estado e a enunciar as bases de todo seu regime legal, tanto no direito público como no privado; dogmático e particular, o segundo, que remodela a Família para ajustá-la a certa concepção socialista - a soviética, antes - a democracia popular - agora - e que para êsse fim formula um corpo legal separado, que se anuncia dirigido para suprimir $\circ$ antagonismo entre 0 interêsse do Estado capitalista e $\circ$ interêsse da Família a que protege em si mesma e cujo fortalecimento e preservação como entidade propugna atualmente depois de superar a etapa inicial de dissolução do grupo e dissociação de seus integrantes. Repercussão diferente têm conseguido êsses dois movimentos renovadores da técnica legislativa.

O primeiro dêles, por sua generalização universal e por estar desprovido de carater dogmático, tem sido aceito pela maioria das constituições modernas, ainda que com intensidade variável e representa uma das características do constitucionalismo social e constitucionalização do direito privado, a fim de que êste se ajuste às bases expressas na Constituição.

Cabe advertir, todavia, que êste sistema não significa o acolhimento da tese do Direito de Família como direito público, ainda que - mesmo se proceda com os princípios fundamentais da propriedade, do trabalho, da atividade econômica, da assistência social, da cultura, da educação, etc.

Ao contrário disto, tanto por sua identificação com o sistema político acima indicado, como pela manutenção dos princípios clássicos, a autonomia legal do Direito de Família tem merecido escassas manifestações de apoio.

Podemos verificar que, de forma integral, assim se procede, com o Código de Família na Rússia, 1918, e reformado várias vêzes para corrigir excesso dessa tendência; Yugoslavia - 1946; Bulgária - sob a denominação da Lei Sôbre as Pessoas e a Família 1949, Checo-Eslováquia, 1950. Êste sistema soviético e das chamadas democracias populares continua isolado. 
O Decreto-lei francês de 29 de julho de 1939 traz a denominação de "Código da Família", mas essa designação é inexata ou incorreta, não só porque se denomina decreto relativo à Família e à natalidade francesa, principalmente porque não subtrai ao Código Civil o regime familiar, modificando apenas algumas das normas dêsse corpo legal.

Na própria Alemanha nazista, o chamado Volks Gezełz Buch - Código do Povo Alemão - manteve a unidade tradicional do Código Civil nesse particular, apesar do movimento doutrinário de seus poderosos juristas que propugnavam a mudança das normas sôbre a Família para o direito público.

Nada adiantou o movimento de CICU - na Itália - com seu Direito de Família, defendendo ardorosamente a tese da inclusão do Direito de Família no direito público, para depois transacionar uma divisão tripartite do Direito: direıto público, direito da família, direito privado.

Em face às reiteradas manifestações de técnica legislativa moderna, adotamos, como melhor solução, o sistema das bases da estrutura da Família - por ser inerente à estrutura social e discordamos da autonomia legal do Direito de Família, pois entendemos que o mesmo integra o Direito Civil.

A conclusão prática que se extrai da renovação da técnica legislativa é que agora o Direito de Família se compõe de duas categorias de regras: umas - orientadoras ou básicas - as constitucionais; e outras - reguladoras - as civis.

O Código Português pertence à segunda dessas categorias, ao contrário do Direito Brasileiro que se filia à primeira. Entendemos, concessa venia, que melhor consulta os interêsses do Direito o princípio da ordenação constitucional, para maior segurança das normas referentes à Família.

Esta profunda renovação no Direito de Família, com aberturas amplas para a conceituação de outras formas de união toleradas pelos códigos modernos ou pelo direito pretoriano ao decidir sôbre casos da vida corrente, não teve eco no Direito Português, inclusive atendo-se ainda ao chamado "casamento concordatário" oriundo da Concordata, de 7 de maio de 1940, com a Santa Sé e que constitui uma excrescência em um código moderno.

Somos radicalmente contrários a qualquer união entre a Igreja ou Igrejas e o Estado em matéria de Direito Civil, máxime em se tratando de casamento, cuja regulamentação deverá caber ùnica- 
mente ao Estado. O Código Português reconhece o casamento católico, note-se a expressão - católico - e não como nossa lei brasileira n. ${ }^{\circ} 1.110$, de 23 de maio de 1950 que "regula o reconhecimento dos efeitos civis do casamento religioso".

Ocorre ainda que no Código Português só será possível entre católicos, afastadas as outras crenças, o que constitui uma discriminação odiosa em um Estado leigo, sendo de notar que, a exemplo da descaída do Código no art. 298 n. ${ }^{\circ} 3$, quanto à extinção do direito de propriedade pelo não uso, apesar do disposto no artigo $1.589, \mathrm{n}^{\circ}$ 1 , do mesmo Código, "o casamento católico contraído por pessoas já ligadas entre si por casamento civil não dissolvido é averbado à margem do assento, independentemente do processo preliminar de publicações", quando no mesmo artigo, em o n. ${ }^{\circ} 2$, determina: "Não é permitido o casamento civil de duas pessoas unidas por matrimônio católico anterior". Melhor seria que o Código se abstivesse dessa regulamentação, denunciando o Estado a Concordata de 1940, por prejudicar, evidentemente a evolução do Direito Civil, nessa parte, com grave ofensa aos princípios jurídicos mais modernos da ciência do Direito Civil, como se viu atrás.

\section{PROMESSA DE CASAMENTO}

Código insere, no Cap. II do Tít. II do Livro IV, a "Promessa de Casamento", embora assinale expressamente que a mesma "não dá direito a exigir a celebração do casamento, nem a reclamar, na falta de cumprimento, outras indenizações que não sejam as previstas no artigo 1.594, mesmo quando resultantes de cláusula penal“.

O Código Francês não registra a promessa de casamento fiançailles -. Os redatores do referido Código guardaram silêncio sôbre as fiançailles e após algumas hesitações, a jurisprudência fixouse definitivamente, por um aresto da Câmara Civil da Côrte de Cassação, decidindo que: "Elle refuse de reconnaître la promesse de mariage comme un contrat valable; aucune obligation civile ne naît des fiançailles".

Apenas a jurisprudência decidiu, em acréscimo, com base nos princípios gerais da responsabilidade civil, que o fiancé que rompe sua promessa pode, em virtude do art. 1.382 do C. Civil, ter responsabilidade pelo fato.

O Código Brasileiro não registra a promessa de casamento e fira reparação de qualquer dano eventual, em caso de arrependimento ou retratação do arrependimento, aplica-se, para que subsista semelhante responsabilidade, a regra do art. 159 do Código, 
segundo a qual fica obrigado a ressarcir aquêle que, por ação ou omissão voluntária, negligência ou imprudência, violar direito ou causar prejuízo a outrem.

Melhor seria que o atual Código Português se abstivesse no seu corpo de leis civis dessa obsolência, embora o BGB também o registre em seus arts. 1.297 e segs.. A atitude do Direito brasileiro é mais apropriada, com a aplicação do disposto no artigo 159.

\section{CASAMENTO INEXISTENTE}

O diploma português prevê, no art. 1.628, o casamento inexistente. Já não se cogita mais, no Direito Civil moderno, dêsse fato inábil à produção de consequiências jurídicas. Tem razão WASHINGTON DE BARROS MONTEIRO quando ensina que "a rigor nem precisa se declare a ineficácia por decisão judicial porque êle nunca existiu juridicamente, nem se torna possível destruir o que não existe". VENZI, em seu Manuale di Diritło Civile, afirma que: "as hipóteses em geral apresentadas - identidade de sexos, ausência de consentimento e falta de celebração constituem os casos geralmente apontados pelos tratadistas para indicar o casamento inexistente que não pode, de modo algum, sanar-se pela ratificação ou prescrição e assim não é necessário recorrer-se à noção de inexistência para se aplicar que, nas situações referidas, o casamento é nulo".

\section{ADOÇÃO}

O código de 1966 incluiu a adoção como fonte das relações de Família. O de 1867 não incluíra o instituto no elenco de suas disposições. O jurista MANUEL DUARTE GOMES, autor do Anteprojeto do instituto da adoção, informava que "a adoção é um instituto que não tem tradição entre nós".

"Ao que parece, mesmo nos tempos màis recuados em que era admitida na nossa ordem jurídica, nunca ela foi praticada com freqüência, e o certo é, pelo menos, que caiu em completo desuso há algumas centenas de anos".

O autor do Código de 1867, VISCONDE DE SEABRA, julgava que não se deveria fazer renascer a adoção, instituto que, a seu ver, repugnava profundamente à natureza humana. Os argumentos de SEABRA não convencem. Por tôda parte se tem demonstrado um grande interêsse pelo instituto que se encontra, em alguns países, como o nosso, em pleno desenvolvimento. 
É verdade que LAFAYETTE, em observação ao $\S 130$ do seu Direito de Família, considera a adoção um instituto obsoleto, deixando de tratar dela. Os Direitos argentino e chileno, de cujos códigos civis não consta o instituto, têm o mesmo regulado, muito depois da sanção daqueles diplomas, por leis extravagantes. O Código Português regulou bem a adoção, com boa técnica e segurança, permitindo nos art. 1.973 a 2.002, a adoção plena e a restrita, de acôrdo com os princípios do direito moderno.

Nesse particular, o nôvo Código acompanhou os Direitos francês e inglês. Limitou bastante a adoção plena, co mexigências mais rigorosas para sua permissão, fundado no princípio de que "sendo a adoção plena equiparada em regra, à filiação legítima, com supressão dos laços que prendem o adotado à família natural, a constituição dela só é justificada quando, por ser a família natural prática ou legalmente desconhecida, não haja probabilidade de competição desta com a família adotiva".

De outro lado, a adoção restrita atende aos interêsses do adotado, propiciando ao adotante a oportunidade de conceder àquele "tôda a proteção que não lese as expectativas da descendência legítima".

Há pequenas diferenças entre a adoção plena do Direito português e a lei brasileira n. $^{\circ} 4.655$, de 65 , que dispõe sôbre a legitimidade adotiva: assim, no diploma português exige-se que o casal adotante esteja casado há mais de 10 anos e na lei brasileira, 5 anos. Em ambos os direitos, o português e o brasileiro, a adoção plena é irrevogável.

Em matéria sucessória, no caso de adoção plena ou legitimidade adotiva, os dois diplomas legais, o nosso e o luso, correm pareIhos. O legitimado adotivo tem o mesmo direito do filho legítimo, salvo no caso de sucessão, se concorrer com o filho legítimo superveniente à adoção, caso em que se aplica a regra do art. 1.605, § $2 .^{\circ}$ do C. Civil Brasileiro ou seja "Ao filho adotivo, se concorrer com legítimos supervenientes à adoção tocará sòmente metade da herança cabível a cada um dêles."

É curioso observar que o projeto brasileiro de C. Civil é inferior, em sua estrutura, à lei 4.655, que é mais liberal e completa. Nota-se essa condição do Relatório da Comissão Revisora, constituída dos juristas OROSIMBO NONATO, ORLANDO GOMES e CAIO MÁRIO DA SILVA PEREIRA, dirigido ao Ministério da Justiça, a respeito da "imiłatio familiae". 


\section{STATUS DA MULHER CASADA}

O diploma português inova nesse particular, afirmando a maior independência da mulher casada e a que ANTUNES VARELLA, na esteira de outros lusos, chama de "progressiva emancipação econômica da mulher".

Efetivamente, o Código luso trouxe direitos extraordinários à mulher casada. No regime do Cód. de 1867, a mulher casada não podia publicar seus escritos, sem consentimento do marido - art. 1.187; a administração de todos os bens do casal pertence ao marido - art. 1.189; incapacidade patrimonial da mulher casada irt. 1.193 e muitas outras disposições restritivas da liberdade da mu'her casada que o atual diploma, não só revogou, mas acresceu outras liberalidades como desnecessidade do consentimento do marido frara exercer profissões liberais ou funções públicas, ou para publicar ou fazer representar as obras ou dispor da propriedade intelectual; o exercício de outras atividades lucrativas, mediante contrato com terceiros, não depende igualmente do marido e outras disposições constantes do art. $1.678 n .^{\circ} 2$, que beneficiam a mulher no regime civil português. É certo que o status da mulher casada em Portugal apresenta melhoras apreciáveis em relação ao diploma de 1867. Todavia, fôrça é convir que a regulamentação das dívidas contraídas pelo marido e constante do art. 1.682 do Cód. Civil atual iá se achava prevista desde 1946, pelo Dec. 19.126, anterior, portanto, à nossa Lei n. ${ }^{\circ} 4.121$, de 1962, em seu art. $3^{\circ}$.

É interessante observar que, na época, o Ministro da Justiça de Portugal, em nota oficiosa, justificava a medida, alegando que: "o artigo 1.114 tem por fim evitar que o credor seja ludibriado e não encontre à dissolução do matrimônio bens à vista por onde possa pagar-se".

Parece-nos que no caso brasileiro, a intenção foi proteger a mulher mais que eventuais credores e é de observar ainda que, sem embargo das disposições claras da lei portuguêsa, a lei brasileira 4.121 está melhor orientada e mais clara e, além disso, consigna maior soma de liberalidade à mulher casada, em nosso regime civil. Basta ver, verbi grałia, que o art. 1.674 do Código Português, referindo-se ao "poder marital", expressão que conserva um pouco de reminiscência da manus romana, enuncia: "o marido é o chefe da família, competindo-lhe nessa qualidade representá-la e decidir em todos os atos da vida conjugal comum". 
Entretanto, a lei brasileira 4.121, além de omitir a expressão "poder marital", é mais atenuada, acentuando a colaboração da muIher e falando em "chefia" da sociedade conjugal art. $1 .^{\circ}, \mathrm{n} . .^{\circ}$ II "o marido é o chefe da sociedade conjugal, função que exerce com a colaboração da mulher, no interêsse comum do casal e dos filhos".

\section{REGIME DE BENS NO CASAMENTO}

O Código luso, como o Projeto Brasileiro, acolhe o regime de bens supletivo, ou seja, que na falta de convenção antenupcial, o casamento considera-se celebrado sob o regime de comunhão dos adquiridos. O projeto brasileiro, em seu art. 160, instituiu o regime normal da separação de bens, salvo estipulação em contrário em pacto antenupcial ou no têrmo de casamento. O Direito francês, em art. 1.400 do Code Napoléon, estabelece o regime da comunhão "à défaut de contrat".

A tendência atual parece ser a do regime legal ou normal da separação de bens. Os civilistas realmente criticam o regime legal da comunhão, dizendo que êle apresenta graves inconvenientes para os interêsses da mulher, postos ao inteiro arbítrio do marido. WASHINGTON DE BARROS MONTEIRO afirma: "Realmente, os riscos existem".

"É bastante freqüente a dilapidação dos bens da mulher pelo marido; nos casos de separação do casal, na simulação de dívidas, com ○ fito de fazer desaparecer a meação da primeira".

"O regime de comunhão é ainda aquêle que melhor favorece as ambições dos caça-dotes e das pescadeiras de maridos ricos". Isto foi escrito na edição $6 .^{a}$ de seu curso de Direito Civil sôbre Direito de Família, já na vigência da Lei 4.121, de 1.962 .

Faltou atualização, pois agora, com a citada lei, muitos dêsses perigos desaparecem, principalmente no que tange ao desaparecimento de meação da mulher, em face ao art. $3 .^{\circ}$ do diploma legal, em causa, que resguarda essa meação.

O Código da Alemanha, país onde, na opinião de MEULENAERE, existem mais de 100 espécies de regimes matrimoniais, ali se adota a chamada comunhão de administração (Verwaltungsgemeinschaft). Parece-nos andou bem o nôvo Código, adotando o regime legal da comunhão de adquiridos e que o Projeto Brasileiro denomina de "regime de separação de bens com comunhão de aqüestos". 
Tanto no Código luso como no Projeto Brasileiro houve rompimento da tradição do regime universal de bens.

A matéria é bem regulada no Código Português, devendo-se notar que, apesar dos pontos de contato com o Projeto Brasileiro, êste apresenta linguagem mais sóbria, sem prejuízo de sua clareza.

\section{PÁTRIO PODER}

O Código Português denomina o Pátrio Poder de "Poder Paternal". E não só a expressão parece mais restrita que a de nosso Código, querendo referir-se apenas ao pai, o que de fato é, como se vê do art. 1.881, pois os direitos da mãe consignados no art. 1.882 são pràticamente irrelevantes, como também continua a refletir sabor antigo do predomínio e ascendência de direitos do marido sôbre a mulher, trazido do velho Code Napoléon cujo artigo 213 rezava: "Le mari doit protection à sa femme, la femme obéissance à son mari".

Assim, o diploma português diz: "Compete ao pai como chefe da família" e discrimina o elenco de seus podêres. Nosso Código é harmonioso, quando diz, no art. 384: "Compete aos pais quanto à pessoa dos filhos menores". É mantido no Código Português o Conselho de Família, reduzidos seus membros a dois, em lugar dos 5 do antigo Código de 1867. Parece-nos instituição obsoleta e sem eficiência, podendo as suas atribuições ser exercidas pelo Ministério Público, como em nosso Código, no que se refere ao contrôle da tutela.

É um velho resquício da influência do Código francês, em cujo artigo 405 lá se encontra o instituto.

\section{FILIAÇÃO ILEGÍTIMA}

Reconhecimenio. $O$ nôvo Código prevê, com minúcias, em seus arts. 1.852 e segs., os diversos modos de reconhecimento judicial da paternidade ilegítima.

Há algumas diferenças do Direito brasileiro. Assim, os filhos incestuosos podem ser reconhecidos, art. 1.869, o que não ocorre no Direito brasileiro, mesmo após a Lei 883 , de 21 de outubro de 1949, permitindo o reconhecimento apenas para os simplesmente naturais e os adulterinos a patre.

Pelo nosso Direito, aquêles - os naturais, são reconhecidos a qualquer tempo; êstes os adulterinos, só podem sê-lo depois da dis- 
solução da sociedade conjugal, a não ser quanto aos filhos, a hipótese da putatividade do casamento, decorrente da boa-fé dos cônjuges ou de um dêles apenas, o que atua no sentido de apagar o vício de origem.

Há no diploma luso uma disposição interessante sôbre o reconhecimento, a legitimação de filhos pelo casamento. É a do art. 1.873. Refere-se aos filhos havidos pelos contraentes antes da celebração do casamento considerado putativo e que ficam considerados legítimos.

O nosso Código, art. 337, determina: "São legítimos os filhos concebidos na constância do casamento, ainda que anulado, ou mesmo nulo, se se contraiu de bôa fé". No art. 217 diz: "A anulação do casamento não obsta à legitimidade do filho concebido ou havido, antes ou na constância dêle".

O que faz equiparar a disposição do art. 1.873 do Código português, isto é, também em nosso Direito, a nosso ver a anulação do casamento, em caso de ambos os cônjuges ou se um dêles estava de boa-fé, não obsta seja considerado legítimo o filho havido antes do casamento considerado putativo.

Em nosso Direito Civil, imprescritível é a ação de reconhecimento da filiação. O diploma luso estabelece que: "A ação de investigação de maternidade ou paternidade só pode ser proposta durante a menoridade do investigante ou nos dois primeiros anos posteriores à sua emancipação ou maioridade".

Para não alongar em demasia o que aliás já o fiz, - cansando-vos com estas desalinhadas considerações - quero apenas citar um dos artigos do Código Português, que reflete a seriedade, o cunho moral e o espírito cristão do grande povo português. É uma frase extraída dos Evangelhos e constante dos Mandamentos divinos, e que inserida no Código Português nada representa no aspecto jurídico, mas vale por uma afirmação moral relevante. Nestes tempos em que a dissolução e a desagregação da família é reiterada e lamentàvelmente apontada pelos renomados irmãos MAZEAUD, em suas Leçons de Droit Civil, merece que se the dê destaque. Diz o art. 1.876 do nôvo Código Civil Português: "Dever fundamental dos filhos. - Os filhos devem honrar e respeitar seus pais". 